The many faces of self-control: Tacit assumptions and recommendations to deal with them.

\author{
Marina Milyavskaya \\ Carleton University \\ Elliot Berkman \\ University of Oregon \\ Denise De Ridder \\ Utrecht University
}

This manuscript has been accepted for publication in Motivation Science. Please note that some changes may occur during the copy-editing process, such that the final published version may differ somewhat from this version.

Corresponding author: Marina Milyavskaya, marina.milyavskaya@ carleton.ca

Acknowledgments: This research was supported by a connection grant from the Social Sciences and Humanities Research Council of Canada to M. Milyavskaya and E. Berkman (SSHRC; grant \#611-2015-0162). 


\begin{abstract}
The term self-control is broadly used by both researchers and lay people. However, both the term itself and the research on self-control is full of assumptions that are often unexamined and unchallenged. In this paper, we question many assertions and assumptions about self-control that foster confusion and controversy, including the multitude of processes encompassed by the varied uses of the term "self-control." We describe how these assumptions have caused gaps in the empirical literature, impeded the development of an interdisciplinary knowledge base about self-control, and ultimately slowed scientific progress in this area. Critically, we also present a set of recommendations for conducting research on self-control that would be relevant across theories, areas of inquiry, and disciplines. By bringing these assumptions to light, future research can better focus on issues that are important and foundational but have been relatively neglected by the literature because of their implicit nature. This paper thus raises new avenues for research by highlighting what the field generally assumes but does not test directly.
\end{abstract}

Key words: self-control; self-regulation; motivation 
The many faces of self-control: Tacit assumptions and recommendations to deal with them

Lay people and researchers alike are fascinated by self-control, which is thought to be important for understanding and improving human behavior. At the most basic level, the term 'self-control' has been applied within the psychology literature to a myriad of diverse phenomena ranging from broad individual differences that emerge in childhood and lead to beneficial outcomes throughout the lifespan (Moffitt et al., 2011) to the ability to withhold a button press on a trial in a laboratory task (e.g., Inzlicht \& Gutsell, 2007). The breadth of psychological constructs subsumed under the self-control umbrella has become so wide that the term itself conveys very little information. This limitation presents a challenge to the construct validity of self-control, and therefore its usefulness in advancing scientific knowledge on the subject. We posit that the time has come to revisit the tacit assumptions about self-control as the construct appears in the psychology literature. The purpose of this article is to articulate and reexamine these assumptions and present some recommendations both for individual researchers studying self-control and for new research directions for the field as a whole.

We adopt a broad working definition of self-control to capture the many ways this term is used in the literature. For this purpose, self-control can be defined as the process or behavior of overcoming a temptation or prepotent response in favor of a competing goal (either concurrent or longer-term). Self-control has long been taken to imply a conflict of some form (Ach, 1910/2006), such as between long- and short-term goals or controlled and automatic processes, that is resolved through behavioral inhibition, attention control, or any other kind of strategy aimed at conflict reduction. Indeed, key assumptions about self-control (such as that it involves conflict resolution) are built into the definition but not typically tested. The same holds for the 
assumption that self-control is effortful, which is typically assumed without specifying what is meant by 'effortful' (but see Wright \& Agtarap, 2015). We elaborate further in these definitional issues in discussing the first class of assumptions below.

\section{Jingle-Jangle Assumptions}

The jingle-jangle fallacy in personality research (Block, 1995) refers to using the same name to different constructs (“jingle”; Thorndike, 1904) and using different names for equivalent or highly similar constructs (“jangle”; Kelley, 1927). Several assumptions about self-control, including many definitional assumptions, fall into this category. For example, the term selfcontrol without a qualifier does not distinguish between trait and state forms of self-control, implying that they are equivalent or at least related in some way. A related tacit assumption is that people who are generally high in trait self-control will display greater (state) self-control when faced with a temptation. This is one type of "jingle" assumption. However, there is no consistent association between state and trait measures of self-control. Whereas some studies suggest that high trait self-control is linked to greater state self-control (e.g., DeWall, Baumeister, Stillman, \& Gailliot, 2007), others find the opposite to be true (e.g., Imhoff, Schmidt, \& Gerstenberg, 2014). A meta-analysis found only a very small correlation $(r=.15)$ between delay-of gratification tasks tapping into state self-control with questionnaires assessing trait self-control (Duckworth \& Kern, 2011; see also Saunders et al., 2017). Furthermore, research rarely distinguishes between lack of impulsivity (i.e., not having an impulse) and impulse control, frequently using the term self-control to apply to both and using measures of both interchangeably to tap into 'self-control' (e.g., Moffitt et al., 2011). Generally, research on 
how trait and state self-control, and self-control and impulsivity relate to each other is seriously hampered by definitional and measurement issues as alluded to above.

Examples of the "jangle" assumption in self-control include neighboring constructs such as grit, conscientiousness, and low impulsivity. The relationship between self-control and other related constructs is unclear. And while some researchers have tried to differentiate these constructs (e.g., Duckworth \& Gross, 2014), data stemming from current scales suggest that all are closely related constructs within the conscientiousness domain (Roberts, Lejuez, Krueger, Richards, \& Hill, 2011). Researchers also often use these constructs (as well as others) interchangeably to tap into 'self-control' broadly understood. Indeed, a recent literature search found "over 100 unique self- and informant-report questionnaires" (Duckworth \& Kern, 2011). The jangle assumption is that these are meaningfully distinct constructs because they are called by different names. But, empirically speaking, this assumption does not hold, as discriminant validity is rarely tested. When it is, results suggest more overlap than differentiation (e.g., Credé, Tynan, \& Harms, 2016; Roberts et al., 2011). It would be productive to unify these constructs under a common name, and to reserve new terminology only for constructs that are empirically unique.

An assumption related to jingle-jangle assumptions is that self-control and self-regulation are the same thing. Using these terms interchangeably conflates successful resolution of selfcontrol dilemmas (what we term self-control) with more general goal-directed behaviors (i.e., self-regulation). Indeed, self-regulation broadly refers to any process where an organism regulates its state (Carver \& Scheier, 1982), and also includes other aspects of goal pursuit such as setting goals, switching between goals, and working towards one's goals in the absence of 
tempting alternatives. Self-control, as we define it above, is a specific instance of successful selfregulation.

Recommendations: More careful theorizing and specific empirical evidence is needed to better understand the similarities and differences among constructs that go by the name "selfcontrol" and others that do not but are close empirical relations. We recommend that researchers consider both discriminant and convergent validity here, as well as predictive validity. What does the focal measure of self-control predict that others do not? Also consider what 'trait' in trait self-control refers to: temperament (cf. impulsivity), personality (cf. conscientiousness), motivation (cf. effort), or more of a generalized belief (cf. optimism). If we distinguish between these 'layers' of trait, then it makes sense that there is a relation between, say, impulsivity and self-control but they are not identical. When studying trait self-control, researchers need to ensure that the measures they use tap self-control per se and not an associated construct (selfregulation, impulsivity, etc.); if the latter, they need to be clear on whether and how this distinction might matter for their particular study. Researchers also need to pay closer attention to the distinction between trait and state self-control. As long as trait and state self-control are studied as if they were separate constructs (i.e., by using different theoretical paradigms and assessment procedures) it will be difficult to directly compare them, unless these differences are reconciled (De Ridder, Kroese \& Gillebaart, 2018).

\section{Capacity assumptions}

Some assumptions about self-control stem from the idea that self-control is a skill or disposition, akin to intelligence. Here, it is assumed that self-control is a property of the person, such that some people are 'good' at exerting self-control across various areas of their lives, while 
others are not. Specific capacity assumptions are the notions that self-control is not influenced by motivation and that it applies equally across performance domains (but see Egner, 2008, for an example where this assumption was tested). This set of assumptions is problematic because of the deterministic implications of such a view - if self-control performance is determined only by some capacity, then improving the capacity is the only way to improve self-control (and the positive benefits associated with it). This narrow assumption has lead researchers to focus on interventions to improve or train self-control; the effectiveness of such interventions is small and variable (Beames, Schofield, \& Denson, 2017; Friese, Frankenbach, Job, \& Loschelder, 2017). In contrast, research on nudging (Thaler \& Sunstein, 2008) has shown great strides in improving self-regulatory outcomes by shifting the contexts in which decisions (including self-control decisions) take place, rather than increasing a self-control capacity (e.g., Kroese, Marchiori, \& De Ridder, 2015). Other researchers have also proposed that attention and motivation are crucial to self-control (Kaplan \& Berman, 2010; Kotabe \& Hofmann, 2015; Locke \& Braver, 2008; Milyavskaya \& Inzlicht, 2017a) and are indeed necessary prerequisites for the capacity to engage in self-control (Hofmann, Schmeichel, \& Baddeley, 2012).

Furthermore, the magnitude of the relationship between trait self-control and one's ability to control behaviors differs across domains (De Ridder et al., 2012). For example, approximately $85-90 \%$ of the variance in the attainment of personal goal (over spans ranging from 1 week to 1 year; Milyavskaya, Inzlicht, Hope, \& Koestner, 2015; Werner, Milyavskaya, Foxen-Craft, \& Koestner, 2016) is at the within-person level, suggesting that it is not the case that some people are good at self-control, but rather that people exert self-control in some areas of their lives (i.e., in the service of some goals) better than others. This also aligns with the idea that motivation and attention play an important role in exerting self-control: whereas a person may have the 
capacity to exert self-control in all domains, he or she may be more motivated to actually engage in self-control only in some specific areas of life (Milyavskaya et al., 2015; Tsukayama \& Duckworth, 2010). By focusing on general self-control and ignoring the specific contexts in which self-control is actually exerted, researchers miss out on an important source of variability that can provide rich information on the specific processes underlying successful or unsuccessful self-control.

Recommendation: Distinguish between the capacity to do something and the tendency to do it. Does the person have the cognitive/physical capacity to be "successful"? If so, consider why this capacity is not being engaged - it likely has little to do with the 'amount' of self-control or executive function. Instead, researchers need to pay special attention to the potentially foundational role of attention and motivation, which likely shifts both across domains and across time. For example, what appears to be failed self-control might result from reduced capacity of attention, or a lack of effort to begin with. Future research can examine what motivates people to engage in self-control, how this shifts across time and context, and whether various sources of motivation differentially impact whether self-control attempts are successful.

\section{Normative assumptions}

A final set of assumptions reflect cultural norms and biases that have long permeated the scientific literature on self-control. For example, a common normative assumption is that selfcontrol dilemmas have only two possible resolutions, one representing a "good" goal and another reflecting a "bad" temptation - the proverbial devil on one shoulder and angel on the other. But, of course, restricting participants to just two responses ignores the important roles that problem solving and creativity can play in identifying compromises or alternative responses. There may 
exist situations where a person perceives that they can succumb to the desire and pursue their long-term goal at the same time, even though the conflict between the two is explicitly recognized. In reality, people are confronted with repeated choices over time in which they can alternate between good and bad choices. While some research and theories have addressed this (e.g., goal systems theory, Kruglanski et al., 2002; Fishbach \& Zhang, 2008; De Witt Huberts, Evers, \& De Ridder, 2014), many typical lab tasks ignore this reality and present individuals with only one choice at one time to assess self-control. In many cases, a choice can be (re)construed as involving two valued goals (Scholer, 2014). Going to bed early instead of working on a manuscript can be considered self-control failure, but could also be looked at as success in self-care. The assumption that choosing the temptation is necessarily maladaptive is implicit in the terminology used, as this choice is most commonly described as a 'failure' of selfcontrol.

Researchers also make normative assumptions about the types of goals participants have when they walk into the lab. State self-control is frequently elicited in the lab with paradigms that presume that the participant faces a dilemma between an unwanted behavior to inhibit and the desired 'correct' behavior. This is especially common in measures of executive control such as the Stroop test, but also in measures assessing persistence on some behavior such as persistence on difficult or unsolvable puzzles. Researchers using these paradigms assume that these dilemmas created in the lab represent real dilemmas for the participants, in that participants actually have the goal to do well at the task. Perhaps participants simply disengage from the lab task because the tasks do not represent dilemmas that the participants actually care about (Inzlicht \& Berkman, 2015). This assumption is problematic even for researchers who conceptualize self-control as the overriding of impulses, because there would be no need for self- 
control in the absence of an impulse. Indeed, many common lab tasks used to assess self-control can be gamed to allow participants to succeed without overcoming a temptation or competing response (e.g., by focusing attention on the last letter of each word on the Stroop task, such that no dilemma between automatic and control processes exists).

Recommendation: Researchers should assess participants' beliefs about what their goal or goals are in a situation and how they understood the response options to map on to those goals. Researchers can also consider measuring self-control outcomes in continuous rather than categorical terms. The use of naturalistic decisions where participants can choose from a list or even choose to create their own option would allow for the study of creative problem solving in the face of self-control dilemmas. Also, instead of assuming that participants hold normative goals (e.g., to eat healthfully), researcher need to measure the idiographic goal that participants have in a situation, and make sure that it is salient and prioritized in the experimental context. For example, eating a tasty sweet constitutes self-control failure only when a person both has a dieting goal and desires to act on that goal in the situation, as opposed to, say, an alternative hedonic goal. To truly measure self-control in the lab, researchers need to ensure that participants actually care about the task at hand and view the task as a self-control dilemma, rather than as another boring task that they need to complete as quickly as possible to be able to get out of the lab and go resume their lives. Note that this also taps into issues of motivation (as addressed in the capacity section above). Researchers need to be explicit on what the experiment is intending to test (e.g., self-control, motivation, or both) and what the presumed relations are between those constructs, rather than simply assume all participants are equally motivated.

In addition to refining our lab paradigms, researchers can further focus on studying how self-control naturally unfolds in daily life (e.g., Hofmann, Baumeister et al., 2012; Milyavskaya 
\& Inzlicht, 2017b). This, however, also comes at a cost, as experience sampling studies that examine self-control in vivo raise participants' awareness of dilemmas by explicitly asking them to reflect on whether their desires conflict with long-term goals. New methodologies need to be developed to ensure that research on self-control reflects how self-control is actually used, examining whether and how individuals both recognize the presence of self-control dilemmas and the strategies that are used.

\section{Conclusions}

The aim of this brief paper was to make explicit some of the assumptions that abound in the literature on self-control. These assumptions can hinder scientific progress in understanding self-control by perpetuating specific lines of thinking and research, and obscuring others. We believe that questioning these assumptions can lead researchers to shift their focus onto issues that are important and foundational but have been relatively neglected by the literature because of their implicit nature. Many of the assumptions stem from the field's collective lack of knowledge regarding the actual processes underlying self-control, and also perpetuate it (since it is assumed, it is not examined empirically). The articulation of the assumptions can help guide future research directions, encouraging researchers to empirically test and elaborate on some of these assumptions, and providing new research areas.

The continual lack of consensus on the basic definition of self-control underscores our point that scientists need to be specific about which aspects of self-control they are studying. Although the preponderance in psychology of terms referring to the same construct can be divisive and detract from cumulative knowledge, using the same term to refer to different conceptual phenomena can also lead to further confusion. In the case of self-control, this ambiguity manifests in a multitude of literatures that mostly do no talk to one another despite 
using the same terminology, and have difficulty integrating their findings when they do. By using more precise terms and making our definitions and assumptions explicit, the areas of commonality and divergence throughout these literatures will become apparent. In turn, being able to identify real gaps in scientific knowledge as opposed to mere definitional differences will allow scientists to substantially advance the field. We thus urge researchers to define their terms rather than assume that everyone means the same thing by self-control; use more specific terminology or qualify where appropriate (e.g., 'trait self-control'; 'proactive self-control'), and be explicit about the assumptions that are made in their research. 


\section{References}

Ach, N. (2006). On Volition (T. Herz, Trans.). (Original work published 1910). Retrieved from University of Konstanz, Cognitive Psychology Web site: http://www.unikonstanz.de/kogpsych/ach.htm

Beames, J. R., Schofield, T. P., \& Denson, T. F. (2017). A meta-analysis of improving selfcontrol with practice. In D. T. D. de Ridder, M. A. Adriaanse \& K. Fujita (Eds.), Handbook of Self-Control in Health and Well-Being (pp. 405-417). Abingdon, UK: Routledge.

Block, J. (1995). A contrarian view of the five-factor approach to personality description. Psychological Bulletin, 117(2), 187-215. http://doi.org/10.1037/0033$\underline{2909.117 .2 .187}$

Carver, C. S., \& Scheier, M. F. (1982). Control theory: A useful conceptual framework for personality-social, clinical, and health psychology. Psychological Bulletin, 92(1), 111-135. http://doi.org/10.1037/0033-2909.92.1.111

Credé, M., Tynan, M. C., \& Harms, P. D. (2016). Much Ado About Grit: A Meta-Analytic Synthesis of the Grit Literature. Journal of Personality and Social Psychology,113(3)492511. http://doi.org/10.1037/pspp0000102

De Ridder, D.T.D., Kroese, F.M., \& Gillebaart, M. (2018). Whatever happened to self-control? A proposal for integrating notions from trait self-control studies into state self-control research. Motivation Science, 4(1), 39-49. http://doi.org/10.1037/mot0000062

De Ridder, D. T. D., Lensvelt-Mulders, G., Finkenauer, C., Stok, F. M., \& Baumeister, R. F. (2012). Taking stock of self-control: A meta-analysis of how trait self-control relates to a 
wide range of behaviors. Personality and Social Psychology Review, 16(1), 76-99.

https://doi.org/10.1177/1088868311418749

DeWall, C. N., Baumeister, R. F., Stillman, T. F., \& Gailliot, M. T. (2007). Violence restrained: Effects of self-regulation and its depletion on aggression. Journal of Experimental Social Psychology, 43(1), 62-76. https://doi.org/10.1016/j.jesp.2005.12.005

De Witt Huberts, J. C., Evers, C., \& De Ridder, D. T. (2014). "Because I Am Worth It" a theoretical framework and empirical review of a justification-based account of selfregulation failure. Personality and Social Psychology Review, 18(2), 119-138.

https://doi.org/10.1177/1088868313507533

Duckworth, A., \& Gross, J. J. (2014). Self-control and grit related but separable determinants of success. Current Directions in Psychological Science, 23(5), 319-325. https://doi.org/10.1177/0963721414541462

Duckworth, A. L., \& Kern, M. L. (2011). A meta-analysis of the convergent validity of selfcontrol measures. Journal of Research in Personality, 45(3), 259-268. https://doi.org/10.1016/j.jrp.2011.02.004

Egner, T. (2008). Multiple conflict-driven control mechanisms in the human brain. Trends in Cognitive Sciences, 12, 374-380. https://doi.org/10.1016/j.tics.2008.07.001

Fishbach, A., \& Zhang, Y. (2008). Together or apart: when goals and temptations complement versus compete. Journal of Personality and Social Psychology, 94(4), 547-559. https://doi.org/10.1037/0022-3514.94.4.547 
Friese, M., Frankenbach, J., Job, V., \& Loschelder, D. D. (2017) Does self-control training improve self-control?: A meta-analysis. Perspectives on Psychological Science, 12(6), 1077-1099. https://doi.org/10.1177/1745691617697076

Hofmann, W., Baumeister, R. F., Förster, G., \& Vohs, K. D. (2012). Everyday temptations: an experience sampling study of desire, conflict, and self-control. Journal of Personality and Social Psychology, 102(6), 1318-1335. https://doi.org/10.1037/a0026545

Hofmann, W., Schmeichel, B. J., \& Baddeley, A. D. (2012). Executive functions and selfregulation. Trends in Cognitive Sciences, 16(3), 174-180.

https://doi.org/10.1016/j.tics.2012.01.006

Imhoff, R., Schmidt, A. F., \& Gerstenberg, F. (2014). Exploring the Interplay of Trait SelfControl and Ego Depletion: Empirical Evidence for Ironic Effects. European Journal of Personality, 28(5), 413-424. https://doi.org/10.1002/per.1899

Inzlicht, M., \& Berkman, E. (2015). Six questions for the resource model of control (and some answers). Social and Personality Psychology Compass, 9(10), 511-524. https://doi.org/10.1111/spc3.12200

Inzlicht, M., \& Gutsell, J. N. (2007). Running on empty: Neural signals for self-control failure. Psychological Science, 18(11), 933-937. https://doi.org/10.1111/j.1467$\underline{9280.2007 .02004 . x}$

Kaplan, S. and Berman, M.G. (2010). Directed attention as a common resource for executive functioning and self-regulation. Perspectives on Psychological Science, 5(1), 43-57. https://doi.org/10.1177/1745691609356784 
Kelley, T.L. (1927). Interpretation of Educational Measurements. Yonkers-on-Hudson, N.Y.: World Book Company. pp. 62-65.

Kotabe, H. P., \& Hofmann, W. (2015). On integrating the components of selfcontrol. Perspectives on Psychological Science, 10(5), 618-638. https://doi.org/10.1177/1745691615593382

Kroese, F. M., Marchiori, D. R., \& de Ridder, D. T. (2015). Nudging healthy food choices: a field experiment at the train station. Journal of Public Health, 38(2), e133-e137. doi:10.1093/pubmed/fdv096

Kruglanski, A. W., Shah, J. Y., Fishbach, A., Friedman, R., Chun, W. Y., \& Sleeth-Keppler, D. (2002). A theory of goal systems. Advances in Experimental Social Psychology, 34, 331378. https://doi.org/10.1016/S0065-2601(02)80008-9

Locke, H. S., \& Braver, T. S. (2008). Motivational influences on cognitive control: behavior, brain activation, and individual differences. Cognitive, Affective, \& Behavioral Neuroscience, 8(1), 99-112. https://doi.org/10.3758/CABN.8.1.99

Milyavskaya, M., \& Inzlicht, M. (2017a). Attentional and motivational mechanisms of selfcontrol. In D.T.D. de Ridder, M. A. Adriaanse, and K. Fujita (Eds). Handbook of SelfControl in Health and Well-Being (pp. 11-23). Abingdon, UK: Routledge.

Milyavskaya, M., \& Inzlicht, M. (2017b). What's so great about self-control? Examining the importance of self-control and temptation in predicting real-life depletion and goal attainment. Social Psychological and Personality Science, 8(6), 603-611. https://doi.org/10.1177/1948550616679237 
Milyavskaya, M., Inzlicht, M., Hope, N. \& Koestner, R.(2015). Saying 'No' to temptation: 'want-to' motivation improves self-regulation by reducing temptation rather than by increasing self-control. Journal of Personality and Social Psychology, 109, 677-693. https://doi.org/10.1037/pspp0000045

Moffitt, T. E., Arseneault, L., Belsky, D., Dickson, N., Hancox, R. J., Harrington, H., ... Caspi, A. (2011). A gradient of childhood self-control predicts health, wealth, and public safety. Proceedings of the National Academy of Sciences, 108(7), 2693-2698. https://doi.org/10.1073/pnas.1010076108

Roberts, B. W., Lejuez, C., Krueger, R. F., Richards, J. M., \& Hill, P. L. (2014). What is conscientiousness and how can it be assessed? Developmental Psychology, 50, 1315-1330. https://doi.org/10.1037/a0031109

Saunders, B., Milyavskaya, M., Etz, A., Wilson, D., \& Inzlicht, M. (2017). Evidence that reported self-control measures do not assess the ability to override impulses. Mansucript under review. Pre-print DOI: 10.17605/OSF.IO/BXFSU.

Scholer, A. A. (2014). When Saying Yes to the Doughnut is not Saying No to Self-Control: A Hierarchical Approach to Flexibility in Conflict Representation. In J. Forgas \& E. HarmonJones (Eds.). The Control Within: Motivation and its Regulation. (pp. 247-262). New York, NY: Psychology Press.

Thaler, R. H. \& Sunstein, C. R. (2008). Nudge: Improving Decisions about Health, Wealth, and Happiness. New Haven, CT: Yale University Press.

Thorndike, E.L. (1904). An Introduction to the Theory of Mental and Social Measurements. New York: Teachers College, Columbia University. 
Tsukayama, E., \& Duckworth, A. L. (2010). Domain-specific temporal discounting and temptation. Judgment and Decision Making, 5(2), 72-82.

Werner, K. M., Milyavskaya, M., Foxen-Craft, E., \& Koestner, R. (2016). Some goals just feel easier: Self-concordance leads to goal progress through subjective ease, not effort. Personality and Individual Differences, 96, 237-242.

https://doi.org/10.1016/j.paid.2016.03.002

Wright, R., \& Agtarap, S. (2015). The intensity of behavioral restraint: Determinants and cardiovascular correlates. In G. Gendolla, M. Tops, \& S. Koole (Eds.), Handbook of Biobehavioral Approaches to Self-Regulation (pp.287-299). Springer, New York, NY. 